DIW BERLIN

Discussion

Papers

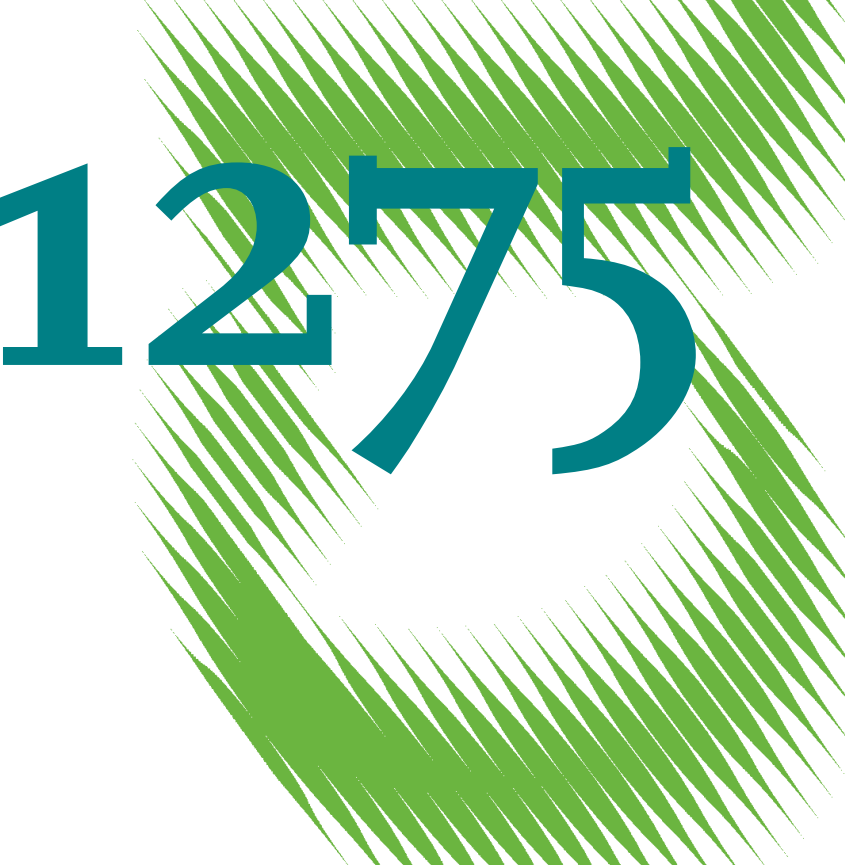

Why Do Emitters Trade Carbon Permits?

Firm-Level Evidence from the European Emission Trading Scheme 
Opinions expressed in this paper are those of the author(s) and do not necessarily reflect views of the institute.

IMPRESSUM

(C) DIW Berlin, 2013

DIW Berlin

German Institute for Economic Research

Mohrenstr. 58

10117 Berlin

Tel. $+49(30) 89789-0$

Fax +49 (30) $89789-200$

http://www.diw.de

ISSN print edition $1433-0210$

ISSN electronic edition 1619-4535

Papers can be downloaded free of charge from the DIW Berlin website:

http://www.diw.de/discussionpapers

Discussion Papers of DIW Berlin are indexed in RePEc and SSRN:

http://ideas.repec.org/s/diw/diwwpp.html

http://www.ssrn.com/link/DIW-Berlin-German-Inst-Econ-Res.html 


\section{Why Do Emitters Trade Carbon Permits? \\ Firm-Level Evidence from the European Emission Trading Scheme}

Aleksandar Zaklan ${ }^{\dagger}$

\footnotetext{
${ }^{\dagger}$ European University Institute and DIW Berlin; aleksandar.zaklan@eui.eu, azaklan@diw.de.

I am deeply grateful to Denny Ellerman and Christian von Hirschhausen. Without them this paper would not have been possible. I also thank Jan Abrell, Jörg Breitung, Franzi Bremus, Jochen Diekmann, Helmut Lütkepohl, Anne Neumann and Vanessa Valero for helpful conversations. However, all errors and omissions are mine. Special thanks go to Rafael Trotignon for sharing his data and Thijs Jong for his help with some of the accounts.
} 


\begin{abstract}
The creation of the EU's Emission Trading Scheme (EU ETS) has turned the right to emit $\mathrm{CO}_{2}$ into a positively priced intermediate good for the affected firms. Firms thus face the decision whether to source compliance with the EU ETS within their boundaries or to acquire it through the permit trade. However, a combination of internal abatement, free permit allocation and flexibility to shift the use of their allocation across time creates opportunities to achieve compliance with the EU ETS without entering the permit trade. This paper aims to identify firm-level determinants of participation in and the extent of the permit trade while recognizing the possibility of zero trade flows leading to selection bias if unaccounted-for. We construct a firmlevel dataset incorporating transaction-level information from both EU ETS operator and person holding accounts, thus representing the entire system-wide permit trade by $\mathrm{CO}_{2}$ emitters. We cover the supply and demand sides of the permit trade, both interfirm and intra-firm, and account for a wide set of firm-level characteristics using firms' balance sheet information. A detailed descriptive analysis documents salient features of the firm-level permit trade. We then jointly model firms' participation and amount decisions while allowing for possible self-selection into trading. Our results suggest that participation in the permit trade is driven by a combination of firm-specific factors existing independently of the EU ETS, such as size, sector and ownership structure, and market-specific characteristics resulting from the firms' inclusion in the EU ETS, such as the value of the firms' free permit endowment and their relative allowance position. We find that amounts traded are mostly driven by market-specific factors. In contrast to the literature on the firm-level determinants of the general goods trade we do not find self-selection into trading.
\end{abstract}

JEL Codes: F14, F18, Q54, C34

Keywords: EU ETS, carbon emission permits, firm-level trade, inter-firm trade, intra-firm trade 


\section{Introduction}

The EU's Emission Trading Scheme (EU ETS) is the first market for carbon emission rights ever brought into operation on a continental scale, affecting all EU countries and a number of industrial sectors. It covers about one half of EU-wide $\mathrm{CO}_{2}$ emissions. The genesis of the EU ETS has given rise to the creation of European Union Allowances (EUAs), each EUA providing its holder with the right to emit one ton of $\mathrm{CO}_{2}$. EU ETS regulations ensure EUA equivalence for compliance purposes, no matter where each particular EUA was issued, making them fully tradable across the entire system. For the firms required by law to be a part of the EU ETS the right to emit $\mathrm{CO}_{2}$ has been turned into a positively priced input factor to their production function, as they now need to surrender permits equivalent to the amount of $\mathrm{CO}_{2}$ they emit during each year.

In the case of a strict system forcing firms to cover their permit needs on the market immediately the link from production decisions to the market for tradable permits would be direct. However, certain features of the EU ETS lead to a weakening of this link. First, during EU ETS Phase I, the period for which the appropriate data are currently available, firms received free endowments of EUAs, which in many cases sufficed to fully cover their permit needs (cf. Ellerman et al. (2010) for a thorough analysis of key features of EU ETS Phase I). Second, in the EU ETS firms are not forced into a static optimization decision between abating and going to the market on the demand side for permits, as well as between increasing emissions, selling surplus permits or leaving them unused on the supply side. Instead, a dynamic component is built into the system. Firms can borrow from their own free permit allocation for the following year and bank unused allowances for future use.

Given the input character of emission permits, the $\mathrm{CO}_{2}$ emitting firm must decide whether to source this particular intermediate good within its own boundaries or trade for it through the market in any given year. ${ }^{1}$ In the case of underallocation with free allowances a firm decides whether to source compliance with EU ETS regulations internally through a combination of abatement and the use of its free allocation or whether to acquire compliance by trading via the EU ETS. If a firm has an overallocation of free allowances it decides whether to keep surplus compliance inside its boundaries or sell it to the market. In both cases firms may find it profitable to generate additional internal abatement and sell

\footnotetext{
${ }^{1}$ On a more general level, outsourcing decisions have received growing attention in the recent literature on the national and international trade in intermediate goods (e.g. Antras and Helpman, 2004).
} 
this surplus on the market. Thus, in principle the combination of internal abatement and free allocation makes it conceivable for firms to remain in compliance with the EU ETS without ever having to participate in the allowance trade. The intertemporal flexibility introduced through borrowing and banking further expands firms' opportunities for nontrading compliance. However, a priori we would not expect to observe a pure non-trading outcome: Firms with a free allocation insufficient to cover its level of emissions may find it inappropriately costly to solely abate internally, while overallocated firms may not not want to bear the opportunity cost of not selling their surplus allowances on the market.

The theoretical literature from the field of environmental economics postulates that differences in marginal abatement costs (MACs) will spur participation in the permit trade, in turn leading to an equalization of MACs across market participants and aggregate cost efficiency in equilibrium (Montgomery, 1972). Given the wide variety of firms represented in the EU ETS we expect that MACs will differ significantly among $\mathrm{CO}_{2}$ emitting firms, providing incentives for trading. However, even with significant MAC differentials some firms may choose not to enter the allowance market in the presence of transaction costs (Stavins, 1995), where in the EU ETS especially the fixed cost may be significant (Jaraite et al., 2010). Additionally, participation decisions may also be influenced by criteria other than rational profit maximization and may lead to asymmetry between the demand and supply sides of an emission trading scheme, with arguments of bounded rationality potentially applying (Simon, 1979; Radner, 1996). ${ }^{2}$ Such considerations may lead to unequal MACs across firms in equilibrium, meaning that less trading may occur than would be expected in the absence of transaction costs (Stavins, 1995). While the existing literature is aware of the potential importance of trading costs in markets for intermediate goods, the microfoundations of such costs are hitherto imperfectly understood (Bernard et al., 2011). However, while information on marginal costs is typically unavailable, both in the EU ETS and in other markets for tradable goods, based on the available evidence we have no reason to believe that the EU ETS is in disequilibrium or subject to noncompetitive behavior (Ellerman et al., 2010). ${ }^{3}$

This paper aims to characterize the determinants of trading behavior by $\mathrm{CO}_{2}$ emitting firms in the EU ETS while considering both participation in and the extent of trading.

\footnotetext{
${ }^{2}$ For instance, firms with an allowance surplus may choose to forgo the possibility of making additional profit from entering the EUA trade in the interest of avoiding additional organizational and decision complexity (Simon, 1979).

${ }^{3}$ If data on MACs were available this would allow us to evaluate the proximity of the observed trade flows to the frictionless equilibrium outcome, i.e. it would help us evaluate the efficiency of the EU ETS.
} 
Our main focus lies on the determinants of the inter-firm trade, both on the demand and supply sides of the EU ETS, which is the relevant area of investigation considering the intermediate good character of EUAs. We note the need to be mindful of a key feature that any study of trade must take into account: As in the trade with any good, a firm can only trade non-negative amounts of emission permits, including zero. The possibility of such a corner solution at zero, i.e. a trading outcome at the corner of the distribution of possible trades, raises the question whether firms that do trade positive amounts represent a random sample from the population of potential traders. Alternatively, selection into trading may be non-random, i.e. self-selection may take place. In the latter case selection bias in coefficient estimates may arise when evaluating the determinants of observed trade flows if we do not account for the possibility of self-selection. Therefore, to establish basic patterns of trading in the EU ETS and motivate the possible need for taking into account the issue of non-random selection a thorough descriptive analysis of the available data is required.

There is a large and growing literature on the firm-level determinants of the trade in goods, both empirical and theoretical (cf. Bernard et al. (2011) for an extensive literature review). Based on pathbreaking theoretical work on trade in the context of heterogeneous firms (e.g. Melitz, 2003), numerous empirical micro studies have analyzed determinants of firm behavior in the goods trade. The literature has established a strong positive link between indicators of firm size and performance and the probability to enter markets for tradable goods (e.g. Bernard and Jensen, 1999). One explanation is that firms may self-select into participating in trading based on above-average productivity, thus being better able to deal with the sunk cost of entry into a new market (Roberts and Tybout, 1997). The literature provides evidence of self-selection both on the sell and buy sides. For instance, Bernard et al. (2010) find evidence of significant selection bias in the decision whether to source intermediate goods within the firm or outside it, with firm productivity also playing a significant role.

The existing empirical literature investigating the EU ETS microstructure is sparse. Jaraite and Kazukauskas (2012) assess the extent of account holder level transaction costs, using data on EU ETS transactions through compulsory installation accounts, operator holding accounts in EU ETS parlance. Trotignon and Ellerman (2008) analyze trading patterns across registries and sectors in the EU ETS based on annual EU ETS compliance data, while Abrell et al. (2011) evaluate the effect of the EU ETS on firm outcome 
variables. The remainder of the existing empirical literature on the EU ETS mostly analyzes EUA spot and futures prices in a time series context. One stream of literature evaluates the fit of particular time series models to the EUA price series (e.g. Benz and Trück, 2009), while another strand estimates the relationship between EUA prices and the prices of energy commodities, such as crude oil, natural gas, hard coal and electricity (Fell, 2010; Hintermann, 2010; Bredin and Muckley, 2011).

This paper aims to contribute to the literature as follows: First, we provide a detailed descriptive overview of trading patterns during the early phase of the EU ETS, which, to the best of our knowledge, has not yet been provided to the same extent. Second, we seek to understand the drivers of $\mathrm{CO}_{2}$ emitting firms' trading behavior by jointly modeling their participation and amount decisions, while allowing for possible self-selection into trading. While focusing our attention on both the demand and supply sides of the inter-firm EUA trade, we also consider intra-firm transfers of allowances. We evaluate the determinants of the intra-firm EUA trade to ascertain whether firms choosing to optimize their allowance portfolio internally are driven by concerns similar to those trading EUAs externally. We test predictions regarding the firm-level determinants of the EUA trade from the general trade literature, such as the greater propensity for participation in trade based on size and performance indicators, as well as the presence of self-selection.

Our analysis is based on a complete set of account-level EUA trade flows involving firms required by law to participate in the EU ETS, using the currently available data on EU ETS Phase I, i.e. the 2005 and 2006 compliance years. ${ }^{4}$ We consider trade flows from both emitters' operator holding accounts (OHAs) and person holding accounts (PHAs). ${ }^{5} \mathrm{We}$ combine these transactions data with balance sheet information on key firm characteristics, such as size, productivity, profitability and ownership structure. We also add data on ex-

\footnotetext{
${ }^{4}$ The 2005 compliance year began in February 2005 and ended at the end of April, 2006. The 2006 compliance year started in May 2006 and ended at the end of April, 2007. It is important to note that the compliance year, the period during which EUAs can be surrendered, is distinct from the period of obligation. Surrender obligations are based on emissions for the respective calender year, while these obligations can be satisfied until the end of the corresponding compliance year, which includes a grace period until the end of April of the following calender year. Thus, when considering firm-level determinants of the allowance trade compliance years are the relevant unit of time.

${ }^{5}$ Each installation, i.e. either factory or power plant, is assigned its own compulsory OHA. During the sample period each installation received a free allocation of EUAs, and at the end of each compliance year a sufficient number of allowances to cover each installation's emissions during the preceding period of obligation must be surrendered from OHAs to achieve compliance with the EU ETS. In contrast, PHAs are established on a voluntary basis, by emitters or other entities wishing to engage in the EUA trade voluntarily. PHAs neither receive free allocations nor can they be used for compliance purposes. However, a number of firms with associated OHAs also held PHAs for convenience, so that it is important to incorporate the latter into any analysis aimed at achieving a complete picture of emitters' trading activities.
} 
post EU ETS compliance. ${ }^{6}$

We estimate a corner solution model for each available cross section, i.e. for the 2005 and 2006 compliance years, using annually aggregated trading data. We find that participation in the carbon permit market is driven by a combination of firm-specific characteristics, which exist independently of the EU ETS, and market-specific factors, which firms exhibit in relation to the EU ETS. In contrast, the firms' decisions on amounts traded are found to be mostly driven by market-specific concerns. Specifically, our results suggest that neither productivity nor profitability affect the decision to participate in the EUA trade. Puzzlingly, the role of firm size differs depending on the side of the market under consideration. The probability to purchase EUAs is positively and significantly affected by firm size, whereas we find no significant impact of size on the probability to sell permits to other firms. Ownership structure and the firm's sector are also significant predictors of participation. We find that firms with a share of government ownership larger than $50 \%$ are more likely to participate in the allowance trade, while majority family-owned firms are less likely to do so. Firms in the industrial sector are found to be less likely to participate in the EUA trade than electric utilities. The estimated effects are also significant economically. In addition, the value of the initial EUA endowment, as well as a firm's ex-post EUA position significantly predict participation on both sides of the inter-firm EUA trade, whereas the effect of the firm's relative EUA position is found to be weaker in the intra-firm trade. The amount of EUAs traded is found to be mostly driven by the value of the firms' free EUA allocation, and to some extent by their ex-post net EUA position at the end of the compliance year. Finally, in contrast to the literature on the firm-level goods trade we do not find a selection bias into EUA trading.

The remainder of the paper is structured as follows. Section 2 introduces the dataset and provides a descriptive overview of the EUA trade. Section 3 describes the methodology used, while results are presented and discussed in Section 4. Section 5 concludes.

\footnotetext{
${ }^{6}$ Shortly after the end of each compliance year the European Commission publishes the amount of verified emissions, as well as the amount of EUAs surrendered for compliance purposes at the installation level for the previous compliance year. Together with the planned allocations, which are also published by the Comission, this information allows us to compute each firm's compliance position, i.e. whether it had a deficit or a surplus of allowances during that particular compliance year.
} 


\section{Data and Descriptive Analysis}

\section{$2.1 \quad$ Data}

We first compile a dataset containing transactions in the entire EU ETS for the calendar period 2005-2007, from the EU Commission's Community Independent Transactions Log (CITL). ${ }^{7}$ We thus obtain full coverage of EU ETS permit flows for the compliance years 2005 and 2006. This dataset contains transactions on the account level, covering government accounts, person holding accounts (PHAs), as well as operator holding accounts (OHAs), i.e. accounts assigned to installations emitting $\mathrm{CO}_{2}$ that are required by law to participate in the EU ETS. Each emitting installation has its own OHA, into which it receives its allocations of EUAs at the beginning of each compliance year, and from which it must surrender the appropriate number of EUAs at the end of each compliance year. An installation is typically a factory or one of several blocks of a large power plant. The data contain information about the amount of EUAs transacted, the time at which the transaction has taken place, as well as some basic information on both parties to the transaction. ${ }^{8}$

However, the transactions data contain no mapping from installations to firms, the relevant unit of analysis, each of which may consist of one or more installations. Therefore, we match the installations from the CITL transactions data to firms, based on the work by Trotignon and Delbosc (2008). To conduct the matching we use additional information on OHAs, also provided by the CITL. The matching covers $83 \%$ of the available aggregate allocations for the 2005 compliance year and $88 \%$ for the 2006 compliance year, which compares favorably to the existing empirical literature on the firm-level determinants of international trade (e.g. Bernard et al., 2009). ${ }^{9}$ We also add annual EU ETS compliance

\footnotetext{
${ }^{7}$ CITL transactions data are released based on calendar years, with a delay of five years. For this reason data going beyond December 2007 are currently unavailable.

${ }^{8}$ It is important to note that the timing of the trade between any two parties may well be different from the timing of the actual transfer of a permit between two parties, which is what the CITL transaction data capture. For instance, a trade may have been agreed to months before a transaction is settled, sometimes via the EUA futures market. For the purposes of our analysis we will assume that both the trade and the transaction between any two firms have taken place within the same compliance year, so that the distinction between the two becomes immaterial, since we consider data aggregated annually, based on compliance years. We thus use terminology such as "buy" and "sell' while being mindful that the available information does not allow us to determine whether each transactions we observe corresponds to a market transaction.

${ }^{9}$ Transactions from the Danish registry could not be matched very well, as the available information on operator holding accounts did not make this feasible. For the same reason, the matching for the Belgian and German registries is also incomplete, although the problem was far less severe in these cases. Furthermore, we had to exclude transactions from the Austrian and Greek registries, as information on domestic transactions in these registries is not available in the CITL transactions database.
} 
data to this dataset, again using the CITL's information on OHAs as a connector.

Additionally, in order to obtain a complete picture of emitters' activities in the EU ETS it is important to consider PHAs, i.e. voluntary trading accounts maintained by a significant number of firms also in possession of compulsory OHAs. Anecdotal evidence suggests that PHAs were also used to manage the firms' overall EUA portfolio, both internally and to purchase or sell additional allowances on the market. Our firm-level transactions dataset thus includes transactions by firms with at least one OHA, regardless of whether transactions were performed through OHAs or PHAs and regardless of whether the counterparty is another firm with affected installations or a financial intermediary. We exclude transactions involving government accounts, as these activities mainly involve the receipt of allowance allocations and the compliance-related surrender of allowances at the end of each compliance year. As the focus of this paper is on the behavior of $\mathrm{CO}_{2}$ emitters, we exclude transactions purely between financial sector companies with no OHAs. Extending the analysis to determinants of trading by the financial sector is left for future work.

However, the CITL data and installation-to-firm matching do not contain information on many relevant firm characteristics. For this reason we collect balance sheet information on these firms, from AMADEUS. In a final step we combine the transactions data with the firm data using our installation-to-firm matching. ${ }^{10}$ In our final dataset we are able to map $73 \%$ and $77 \%$ of EU ETS allocations for the 2005 and 2006 compliance years, respectively, to firms including a full set of firm-level control variables.

\subsection{Descriptive Analysis}

The transactions data with identified companies reveal several interesting patterns (Table 1). Firms in our sample have received allocations of 1,640 and 1,730 million EUAs for the 2005 and 2006 compliance years, respectively. ${ }^{11}$ Accounts controlled by the firms in our sample acquired EUAs for a total of 1,278 million tons of $\mathrm{CO}_{2}$ during the first two compliance years, whereas they disposed of EUAs for 1,270 million tons of $\mathrm{CO}_{2}$ over the same period. However, once we account for intra-firm transfers, we find that 469

\footnotetext{
${ }^{10}$ While EU ETS compliance years run from February of each year to April of the following calendar year, firm data in AMADEUS are reported on a calendar year basis. For our merge we assume that the information contained in the firm control variables is stable between December and April of the following year.

${ }^{11}$ The raw transactions data indicate an overall allocation of 5,925 million tons of $\mathrm{CO}_{2}$ for all three years of ETS Phase I. The discrepancy to the figure reported in Ellerman et al. (2010) appears to be mostly due to the exclusion of transactions from the Austrian and Greek registries.
} 


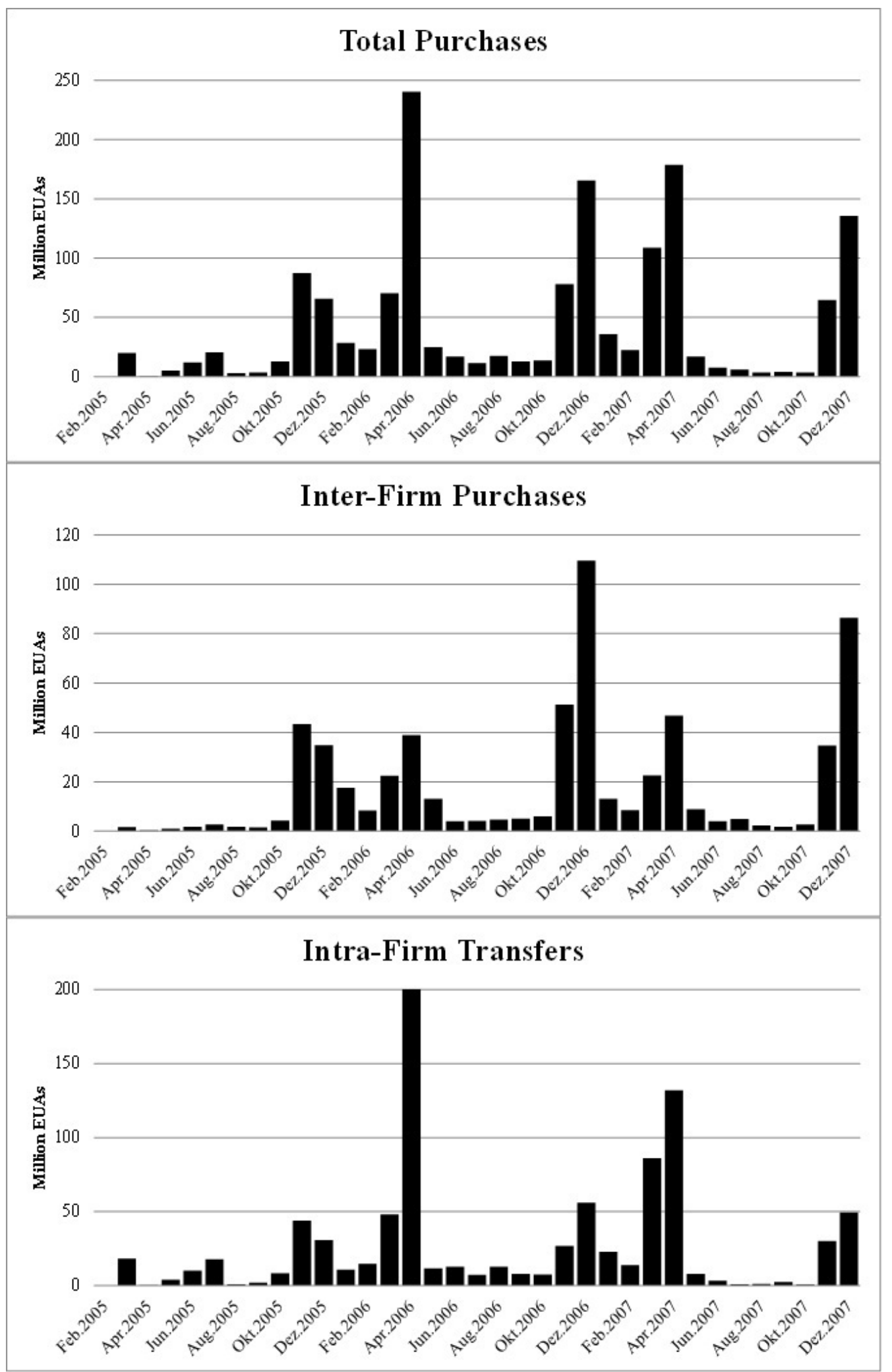

Figure 1: Evolution of Total, Inter-Firm and Intra-Firm Purchases, in Million EUAs 


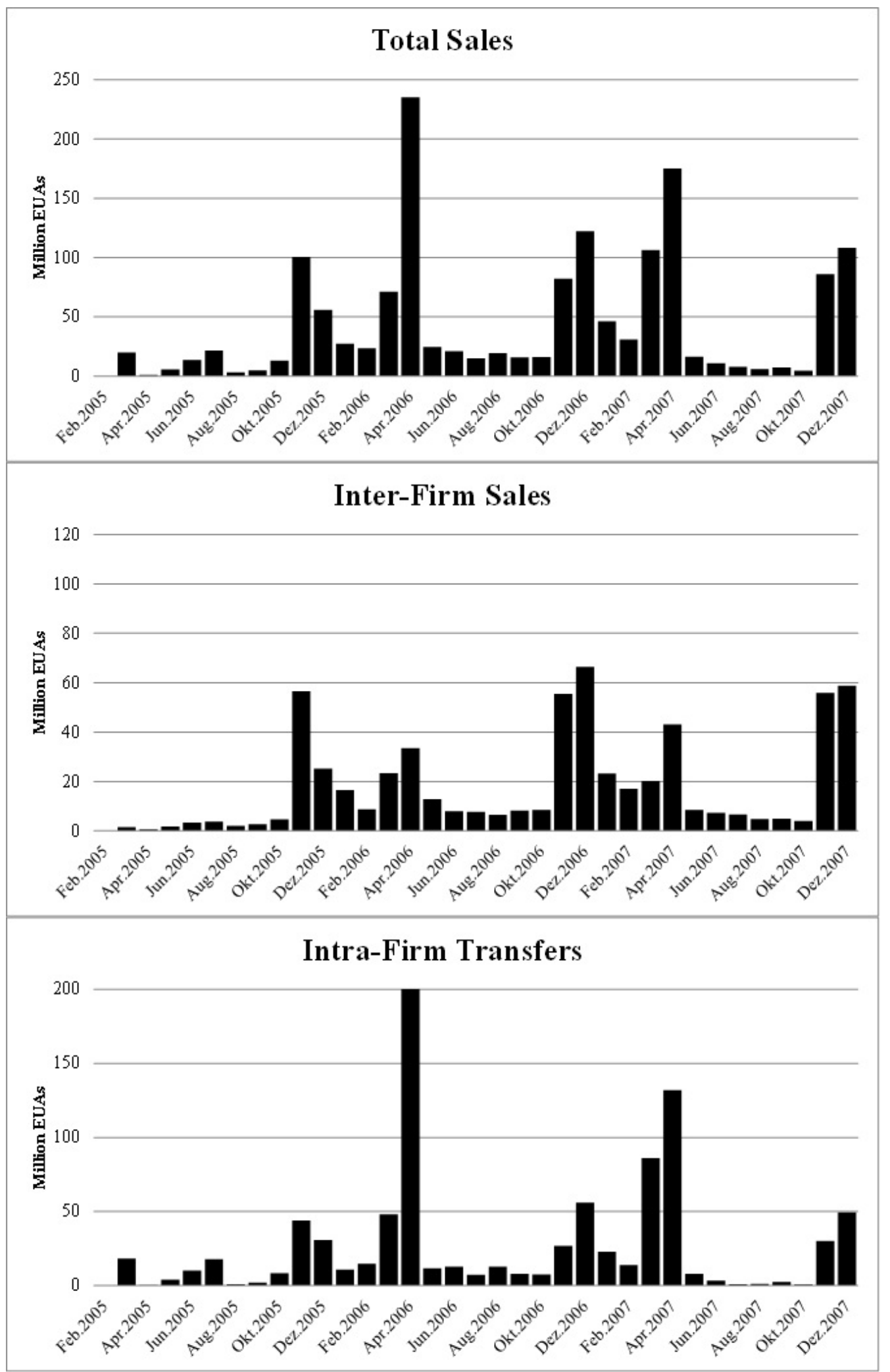

Figure 2: Evolution of Total, Inter-Firm and Intra-Firm Sales, in Million EUAs 
million tons are purchased and 461 million tons are sold beween firms during the first two compliance years. Thus, the majority of allowances are traded internally.

Table 1: EUA Allocation and Trading Patterns for Identified Firms, in Million Tons of $\mathrm{CO}_{2}$

\begin{tabular}{lllllll}
\hline & Allocation & Total Sales & $\begin{array}{l}\text { Inter-Firm } \\
\text { Sales }\end{array}$ & Total Purchases & $\begin{array}{l}\text { Inter-Firm } \\
\text { Purchases }\end{array}$ & $\begin{array}{l}\text { Intra-Firm } \\
\text { Transfers }\end{array}$ \\
\hline 2005 & 1,640 & 596 & 184 & 592 & 180 & 412 \\
2006 & 1,730 & 674 & 277 & 686 & 289 & 397 \\
Sum & 3,370 & 1,270 & 461 & 1,278 & 469 & 809 \\
\hline
\end{tabular}

We can establish an approximate benchmark for the relevant size of the inter-firm market by summing up the absolute values of the firm-level excess allocations, i.e. of the differences between allocations and verified emissions for each company. Doing so yields an overall market size of 450 million tons of $\mathrm{CO}_{2}$ for the first two compliance years combined. While this number is only suggestive, we find it reassuring that the amount of trade roughly compares to the benchmark market size during those years. We next consider the distribution of EUA trading by the firms in our sample over time. We observe that EUA purchases are strongly concentrated at two points of each year, at the end of each compliance year and at the end of each calender year (Figure 1, top panel). Inter-firm purchases are more pronounced at the end of each calender year, when EUA futures are settled (Figure 1, middle panel). In contrast, intra-firm transfers are concentrated at the end of each compliance year (Figure 1, bottom panel), suggesting an internal optimization of allowance portfolios toward the end of each compliance year for a significant number of firms. The pattern on the sell side is similar, although we find that inter-firm sales are somewhat more spread throughout the year compared to inter-firm purchases (Figure 2).

As Table 2 shows, in each compliance year a significant number of firms participated neither in inter-firm nor in intra-firm trading. For instance, out of 608 firms in our dataset that received a positive EUA allocation in the 2005 compliance year and for which we have a full set of firm-control variables available, 261 did not participate in any allowance trading at all (Table 2, left column). ${ }^{12}$

Only 209 companies traded EUAs on both the supply and demand sides. 99 companies only sold while not buying EUAs, whereas for 39 companies the reverse was true. As expected, the majority of the non-participants belong to the group of companies which were long on allowances, whereas only 72 companies which were short on allowances did not

\footnotetext{
${ }^{12}$ The remainder of the descriptive analysis only considers firms for which we have a full set of firmspecific characteristics available for consistency between the samples used for the descriptive analysis and the formal analysis undertaken in Section 4.
} 
participate in trading during the 2005 compliance year. We observe a uniform increase in participation during the 2006 compliance year. The number of companies which received a positive allocation of EUAs increased to 666 (Table 2, right column), as some laggard registries, mainly the Italian and Polish ones, became fully operational. The number of non-participants fell to 204, whereas now 271 companies both bought and sold allowances during the same year. Participation increased for both long and short companies.

Table 2: Participation in Total Trading, by EUA Position

2005 2006

Participation: Sales vs. Purchases, All Companies

\begin{tabular}{rr|rr|l} 
& & \multicolumn{2}{|c|}{ Purchases } & \\
& & 0 & 1 & Total \\
\hline Sales & 0 & 261 & 39 & 300 \\
& 1 & 99 & 209 & 308 \\
\hline & Total & 360 & 248 & 608 \\
\hline
\end{tabular}

\begin{tabular}{rr|lr|l} 
& & \multicolumn{2}{|l|}{ Purchases } & \\
& & 0 & 1 & Total \\
\hline Sales & 0 & 204 & 78 & 282 \\
& 1 & 113 & 271 & 384 \\
\hline Total & 317 & 349 & 666 \\
\hline
\end{tabular}

Participation: Sales vs. Purchases, Long Companies

\begin{tabular}{rr|rr|l} 
& & \multicolumn{2}{|c|}{ Purchases } & \\
& & 0 & 1 & Total \\
\hline Sales & 0 & 189 & 10 & 199 \\
& 1 & 97 & 145 & 242 \\
\hline & Total & 286 & 155 & 441 \\
\hline
\end{tabular}

\begin{tabular}{rr|lr|l} 
& & \multicolumn{2}{|l|}{ Purchases } & \\
& & 0 & 1 & Total \\
\hline Sales & 0 & 157 & 12 & 169 \\
& 1 & 109 & 193 & 302 \\
\hline & Total & 266 & 205 & 471 \\
\hline
\end{tabular}

Participation: Sales vs. Purchases, Short Companies

\begin{tabular}{rr|rr|l} 
& & \multicolumn{2}{|c|}{ Purchases } & \\
& & 0 & 1 & Total \\
\hline Sales & 0 & 72 & 29 & 101 \\
& 1 & 2 & 64 & 66 \\
\hline & Total & 74 & 93 & 167 \\
\hline
\end{tabular}

\begin{tabular}{rr|lr|l} 
& & \multicolumn{2}{|l|}{ Purchases } & \\
& & 0 & 1 & Total \\
\hline Sales & 0 & 47 & 66 & 113 \\
& 1 & 4 & 78 & 82 \\
\hline & Total & 51 & 144 & 195 \\
\hline
\end{tabular}

However, participation is restricted to a small number of transactions per compliance year for most companies. For instance, on the supply side the vast majority of firms either did not trade at all or conducted at most five transactions in either compliance year (Figure 3). However, most firms were not autarkic with regard to allowance management (Figure 4). Only 32 firms exclusively managed their EUA portfolio internally during the 2005 compliance year, as measured by the ratio of total inter-firm trade to total trade, whereas 36 firms did so during the 2006 compliance year. A significant number of firms exclusively relied on the external market and did not shift allowances internally at all, as evidenced by 181 and 262 firms with inter-firm to total trade ratios of 1 during the 2005 and 2006 compliance years, respectively. The remaining firms are spread fairly evenly between the extremes. 


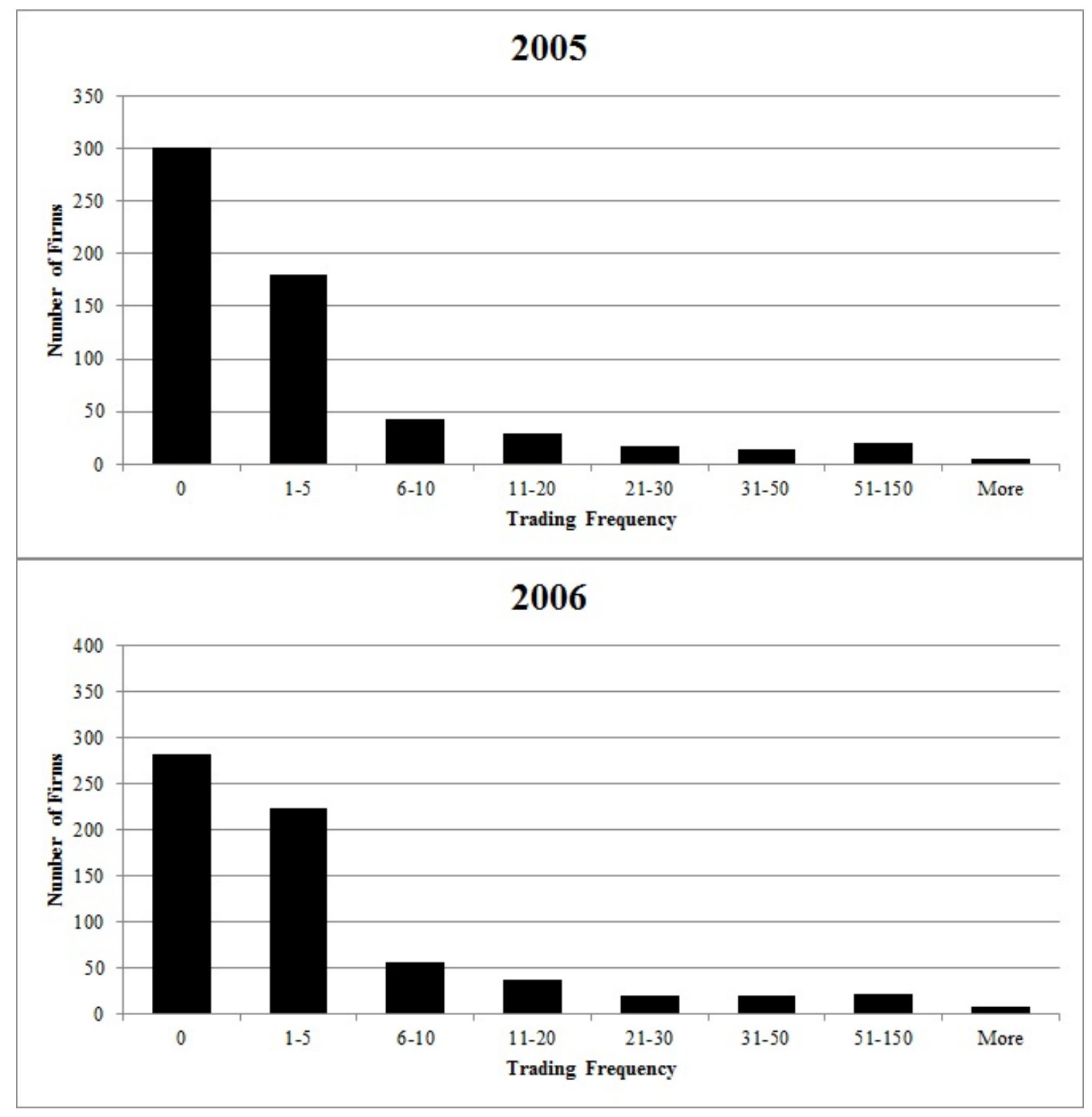

Figure 3: Trading Frequency, Total Sales

Having examined the firm's trading behavior in the EU ETS, we turn our attention to the characteristics of the firms in our sample. Table 3 presents the firms which received a positive allocation during the 2006 compliance year. We observe that the sample is skewed towards large and more profitable firms receiving large EUA allocations. The mean firm had a turnover of 5.6 billion Euro, received an allocation of about 2.3 million EUAs and employed more than 13,000 people. Furthermore, the mean firm was slightly short on EUAs. ${ }^{13}$ However, the median firm was much smaller, with a turnover of less than 400 million Euro, an allocation of 200 thousand EUAs and about 927 employees. It

\footnotetext{
${ }^{13}$ This slight underallocation in our estimation sample is a result of not having a complete set of control variables available for the entire group of identified firms. When considering all identified firms, regardless of availability of control variables, the mean firm is found to be long on allowances.
} 


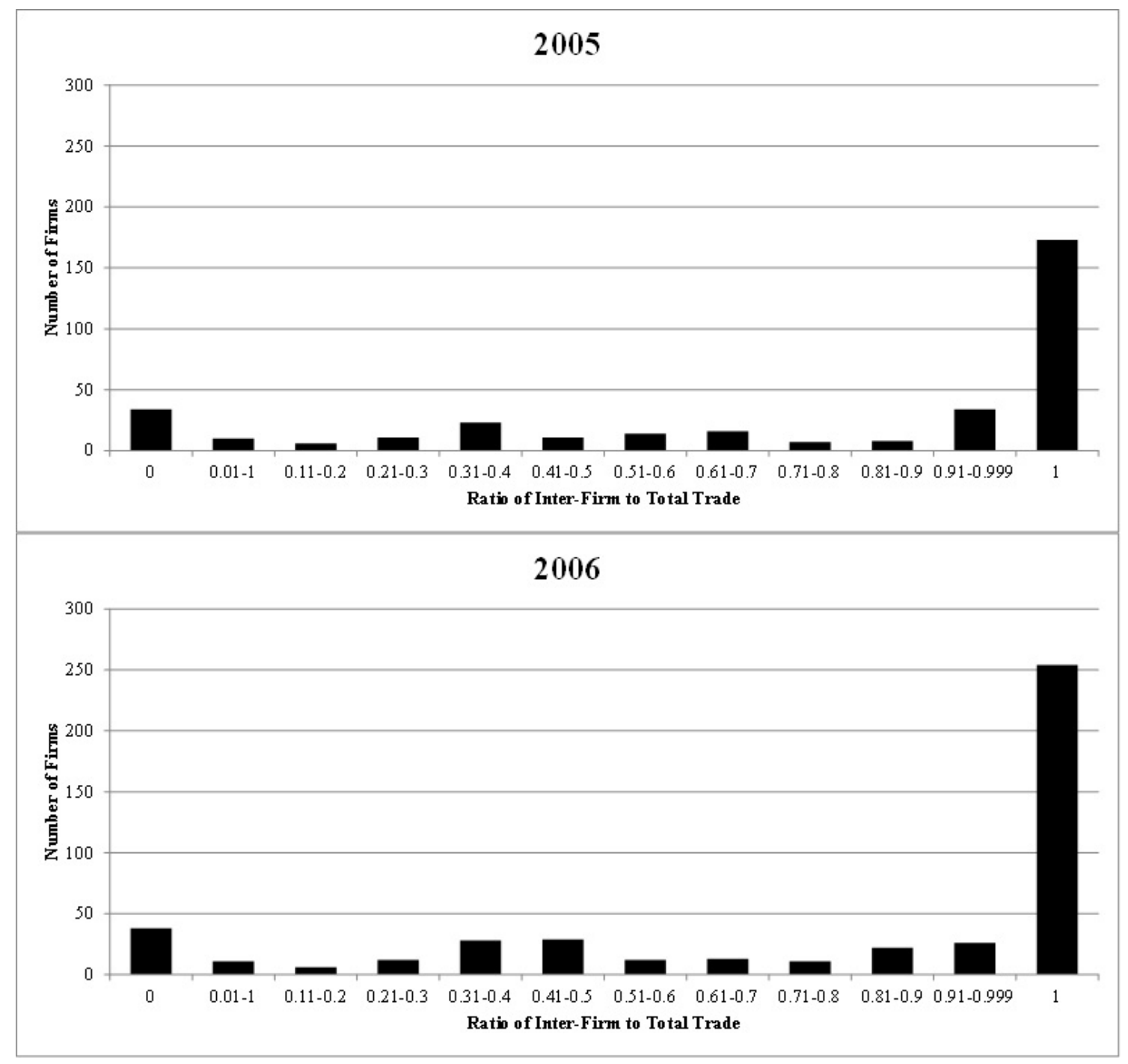

Figure 4: Ratio of Inter-Firm to Total Trade

was also less profitable, with a return on assets of $4.1 \%$. Furthermore, the median firm was significantly long on EUAs. In addition, $28 \%$ of the firms in our sample are majority-owned by the government, while $8 \%$ are majority family-owned. $62 \%$ of the firms are classified as belonging to the combustion category by the CITL, with the remainder having its main 
ETS-related activity in the industrial sector. ${ }^{14}$ The overall range is fairly large according to all these metrics, giving us confidence that while larger firms are over-represented our sample provides a fair picture of the players in the EU ETS.

Table 3: Descriptive Statistics, 2006 Cross Section

\begin{tabular}{lcrrrrr}
\hline Variable & Obs. & Median & Mean & Std. Dev. & Min & Max \\
\hline Allocation (EUAs) & 666 & 199,420 & $2,272,464$ & $9,227,955$ & 4 & $150,000,000$ \\
Verified Emissions (Metric Tons) & 666 & 160,870 & $2,305,223$ & $9,780,751$ & 5 & $157,000,000$ \\
Turnover (Thousand Euro) & 666 & 394,155 & $5,582,238$ & $19,500,000$ & 1,462 & $248,000,000$ \\
Number of Employees & 636 & 927 & 13,539 & 38,697 & 4 & 368,500 \\
Return on Assets (in Percent) & 666 & 4.1 & 5.3 & 6.4 & -17.5 & 51.0 \\
\hline
\end{tabular}

As a final descriptive step we consider the trading patterns in relation to the firms' EUA position and their degree of market activity. Table 4 distinguishes the firms in our two cross sections for which we have a full set of control variables available according to two criteria, the EUA position (long vs. short) and whether the firm has actively managed its EUA portfolio through the EU ETS, i.e. whether it has both sold and purchased EUAs outside its boundaries during the compliance year in question. ${ }^{15}$

For the 2005 cross section we find that the aggregate ex-post EUA position of both groups of long firms, active and less active, was broadly similar. However, this overall allowance surplus is divided among far fewer firms for the group of active companies. Thus, a larger individual allocation appears to be related to stronger involvement in allowance trading. Furthermore, the more active long firms appear to have realized their profit opportunities from selling EUAs more fully during the 2005 compliance year, while the less active long firms only sold about half of their surplus allowances during the 2005 compliance year. Active short firms represent an allocation of about 737 million EUAs in the 2005 cross section, with most of the largest players by allocation size belonging to this group. During the 2005 compliance year this group exhibits net purchases on aggregate,

\footnotetext{
${ }^{14}$ The CITL assigns main activity codes to each emitting installations' account, with each account receiving only one classification. Codes are divided into the following categories: combustion, mineral oil refining, coke ovens, metal ore roasting, pig iron/steel production, cement production, glass production, ceramics production, paper and pulp production, as well as a residual opt-in category. To avoid problems with the estimation of so many separate dummy variables we create the industry dummy variable equaling zero if the main activity type is combustion and one if the activity falls into any of the other categories, excluding the opt-in activity. The reason for singling out combustion is that the largest share of aggregate EU ETS allocations belongs to this category. In many cases this means electricity generation. However, several firms which would be considered industrial concerns have all of their EU-ETS-related installations classified as having combustion as its main activity. For instance, this typically applies for car manufacturers. Since we do not have any other information available to classify the companies by sector and since we do not want to introduce arbitrariness by re-classifying firms by hand, we have kept the CITL classification. Additionally, after matching installations to firms we sometimes find that installations with several activity types belong to the same firm. In this case we categorize the firm as belonging to the industrial sector if the majority of its emissions is caused in installations classified as industrial.

${ }^{15}$ The distinction into active and less active companies is admittedly ad hoc. However, we believe it is useful in structuring our analysis.
} 
while not quite covering its allowance deficit, meaning that the actively trading firms that were short on EUAs resorted to borrowing for the 2005 compliance year. The group of less active firms almost exclusively bought EUAs to cover some of their deficit, but also borrowed significantly as a group, to the tune of almost 9 million EUAs. These trends in aggregate trading behavior led to net banking of about 7 million EUAs in our sample during the 2005 compliance year.

Table 4: EUA Trading Patterns, by Firm Activity and Allowance Position, in Million Tons of $\mathrm{CO}_{2}$

\begin{tabular}{|c|c|c|c|c|c|c|c|c|}
\hline & & Firms & Allocation & $\begin{array}{l}\text { Surplus } \\
\text { Alloca- } \\
\text { tion }\end{array}$ & $\begin{array}{l}\text { Inter- } \\
\text { Firm } \\
\text { Sales }\end{array}$ & $\begin{array}{l}\text { Inter- } \\
\text { Firm } \\
\text { Pur- } \\
\text { chases }\end{array}$ & $\begin{array}{l}\text { Net } \\
\text { Inter- } \\
\text { Firm } \\
\text { Trade }\end{array}$ & $\begin{array}{l}\text { Net } \\
\text { Borrow- } \\
\text { ing }\end{array}$ \\
\hline \multirow[t]{2}{*}{ Long } & Active & $69(11.3 \%)$ & $256.2(17.8 \%)$ & 38.3 & 45.5 & 22.6 & 23.0 & -15.4 \\
\hline & Less Active & $372(61.2 \%)$ & $320.0(22.3 \%)$ & 41.7 & 21.7 & 0.3 & 21.4 & -20.3 \\
\hline \multirow{3}{*}{ Short } & Active & $36(5.9 \%)$ & $736.9(51.3 \%)$ & -68.7 & 90.0 & 138.9 & -48.9 & 19.8 \\
\hline & Less Active & $131(21.5 \%)$ & $123.2(8.6 \%)$ & -20.5 & 0.3 & 12.1 & -11.8 & 8.7 \\
\hline & Sum & 608 & $1,436.4$ & -9.2 & 157.5 & 173.8 & -16.3 & -7.1 \\
\hline \multirow[t]{2}{*}{ Long } & Active & $110(16.5 \%)$ & $446.1(29.5 \%)$ & 47.9 & 106.5 & 53.0 & 57.1 & 5.6 \\
\hline & Less Active & $361(54.2 \%)$ & $284.8(18.8 \%)$ & 38.8 & 34.5 & 0.7 & 32.9 & -5.0 \\
\hline \multirow[t]{3}{*}{2006 Short } & Active & $46(6.9 \%)$ & $630.0(41.6 \%)$ & -84.5 & 96.0 & 211.0 & -119.9 & -30.6 \\
\hline & Less Active & $149(22.4 \%)$ & $152.7(10.1 \%)$ & -24.1 & 4.9 & 17.0 & -12.0 & 12.1 \\
\hline & Sum & 666 & $1,513.6$ & -21.8 & 241.9 & 281.7 & -41.8 & -17.9 \\
\hline
\end{tabular}

Note: Long indicates that the firm's allocation exceeds its verified emissions in the respective compliance year; Active is defined as having conducted at least one inter-firm purchase and sale during the particular compliance year; net inter-firm trade measures the difference between inter-firm sales and inter-firm purchases, while net borrowing captures the difference between net inter-firm trade and surplus allocation for the given compliance year. Negative values of net borrowing indicate that net banking has occurred.

When considering the 2006 compliance year, we notice that the aggregate amount of EUAs covered by our sample increases from 1.44 billion to 1.51 billion tons of $\mathrm{CO}_{2}$, mainly as a result of the Italian and Polish registries becoming operational. The majority of these new entrants appears to have been long on EUAs and actively involved in trading, since the aggregate allocation for this group increases from to 446 million EUAs. Both active and less active long firms sold heavily to other firms. Active short firms became major net buyers during the 2006 compliance year, with net purchases of some 120 million EUAs, roughly covering both their deficit for the 2006 compliance year and their borrowing from the previous year.

\section{Methodology}

The firms in our sample face a twin decision. They first must decide whether to participate in trading at all and, in case they do participate, what amount to trade. This decision 
problem gives rise to the following population model:

$$
\begin{aligned}
& y_{i 1}=x_{i 1} \beta_{1}+\epsilon_{i 1} \\
& y_{i 2}=x_{i 2} \beta_{2}+\epsilon_{i 2},
\end{aligned}
$$

where $y_{i 1}$ denotes the logarithm of the amount of emission permits traded, while $y_{i 2}$ is a dummy variable equaling 1 if the firm trades a positive amount of EUAs and 0 if it does not. Therefore, a positive $y_{i 1}$ is only observed for firms participating in trading, while $y_{i 2}$ is available for all firms in the sample. Thus, firms are faced with a corner solution problem, with the dependent variable being in logarithms. Correspondingly, $x_{i 1}$ is the set of control variables containing information about firms that trade, whereas $x_{i 2}$ consists of covariates for all firms. We assume that $\epsilon_{i 1}$ and $\epsilon_{i 2}$ are normally distributed. Given the selection decision, the regression function for the subset of available data on amounts traded depends not only on $x_{i 1}$ but also on the rule according to which the sample has been selected. Thus, (2) enters the conditional expectation of (1) as follows:

$$
E\left(y_{i 1} \mid x_{i 1}, \epsilon_{i 2}\right)=x_{i 1} \beta_{1}+E\left(\epsilon_{i 1} \mid x_{i 2}, \epsilon_{i 2}\right)=x_{i 1} \beta_{1}+\gamma_{1} \epsilon_{i 2}
$$

Accordingly, the existence of a sample selection bias depends on the correlation between the error terms in (1) and (2). Neglecting this issue by estimating (1) only based on the information from the selected sample can give rise to an omitted variable problem (Heckman, 1979). However, as Heckman (1979) has shown, this bias can be corrected for by including an additional regressor in (1). Using iterated expectations on (3) we obtain

$$
E\left(y_{i 1} \mid x_{i 1}, y_{i 2}=1\right)=x_{i 1} \beta_{1}+\gamma_{1} \lambda\left(x_{i 2} \delta_{2}\right)
$$

where $\lambda\left(x_{i 2} \delta_{2}\right)=\frac{\phi\left(x_{i 2} \delta_{2}\right)}{\Phi\left(x_{i 2} \delta_{2}\right)}$ is the inverse Mills ratio. Estimating (4) yields consistent estimates of $\beta_{1} . \lambda\left(x_{i 2} \delta_{2}\right)$ cannot be directly computed from the data, as it involves the unknown parameter vector $\delta_{2}$. However, it can be consistently estimated using Heckman's (1979) two-step procedure. In a first step we obtain $\hat{\delta}_{2}$ by performing a probit estimation of the probability that firms will participate in trading:

$$
P\left(y_{i 2}=1 \mid x_{i 2}\right)=\Phi\left(x_{i 2} \delta_{2}\right)
$$

In a second step we regress $y_{i 1}$ on $x_{i 1}$ and $\hat{\lambda}(\cdot)$, our estimate of the inverse Mills ratio. A 
simple t-test of $H_{0}: \lambda_{1}=0$ allows us to test for the existence of a selection bias in the firms' amount decision induced by its participation decision. Furthermore, in addition to yielding consistent estimates for the coefficient vector in the amount decision we obtain determinants of the probability to participate in trading, which is also of primary interest in this study. We thus interpret the Heckman (1979) approach as a flexible way of dealing with corner solutions. ${ }^{16}$

In principle $x_{i 1}$ and $x_{i 2}$ can contain identical regressors. However, in the case of identical regressors we rely on the non-linearity of $\hat{\lambda}(\cdot)$ for identification. To avoid a possible collinearity problem, it is desirable to use exclusion restrictions, if applicable, so that $x_{i 1}$ and $x_{i 2}$ differ, i.e. to include variables in the estimation of the firm's participation decision which do not affect its amount decision (e.g. Bernard et al., 2010). We assume that a firm's total size, as measured by turnover, determines participation, while it is not related to the amount decision. ${ }^{17}$ The reason is that firms are covered by the EU ETS unevenly, depending on their activities, so that smaller firms may end up with a larger EUA allocation than large corporations with activities that mostly lie outside the EU ETS. Furthermore, the relationship between turnover and firms' excess allocation amounts, i.e. the difference between allocation and verified emissions, is even weaker. The excess allocation determines whether the firm will tend to be on the supply or on the demand side in the allowance trade, so that a systematic relationship between firm size and excess allocation could be expected to influence the amounts traded. ${ }^{18}$ Instead, we use turnover as a proxy for a firm's ability to overcome the fixed cost of participating in EUA trading, based on the premise that larger firms are more likely to have the resources necessary to overcome the costs of engaging in trading. Our second exclusion restriction is that the ratio of the EUA stock to turnover also only affects participation. This variable serves as a proxy for the firm's incentive to overcome the cost of participating, measuring the relative value of the firm's EUA stock in proportion to its overall size. A larger value of this ratio should provide a greater incentive to engage in trading, especially in inter-firm trading, while the actual amount traded should be driven by the absolute value of the EUA stock only.

\footnotetext{
${ }^{16}$ Given the assumption of log normality in the amount equation the literature also calls this approach the exponential Type II Tobit model (Wooldridge, 2010).

${ }^{17}$ The results are similar when using employment or total assets to capture firm size.

${ }^{18}$ The pairwise correlation coefficients between turnover and the company-level allocation is 0.27 and 0.29 for the full 2005 and 2006 estimation samples, respectively, while the correlations between turnover and excess allocation are -0.1 and -0.08 for the respective full samples.
} 
The remainder of $x_{i 2}$ and all of $x_{i 1}$ are made up as follows: We include the log of the ratio of turnover to total assets as a measure of productivity and the return on assets as a proxy for firm profitability. Dummy variables indicate whether a company was majority government-owned or majority family-owned. Another dummy shows whether a company belonged to the industrial sector or had its ETS relevant activities in combustion. Additionally, we include variables capturing EU ETS specific aspects of the firm. A dummy indicates whether a firm was long on EUAs at the end of the respective period of obligation, i.e. the calender year the respective compliance year corresponded with, based on the difference between its allocation and its verified emissions. Finally, we include the value of the stock of each firm's free EUA allocation. Details on the precise definition of all variables in our dataset, including data sources, can be found in the Appendix.

We conduct separate estimations for cross sections for the 2005 and 2006 compliance years of EU ETS Phase I, since each year displays a distinct evolution of the EUA spot price, and also to capture possible learning effects from one compliance year to the next. ${ }^{19}$ For each cross section we perform estimations for two samples of companies. The full sample contains information on all companies for which the full set of data is available, while the less-active sample excludes firms that have both bought and sold EUAs at least once during the same compliance year. Thus, the less-active sample excludes the observations for the latter firms from both stages of the estimation, while the number of observations for the firms that do not participate in the EUA trade during the year in question remains unchanged. This means that the ratio of censored to non-censored observations increases for the case of the less-active sample. With this, admittedly rough, criterion we aim to distinguish between firms that managed their allowance portfolio actively from those that may have bought and sold mostly based on residual concerns.

\footnotetext{
${ }^{19}$ We do not report results for 2007 , for two reasons. First, data availability does not allow for a complete picture of the trading behavior during that year. Transaction data are currently only available through the end of the 2007 calendar year, whereas most of the trade for both the 2005 and 2006 compliance years took place during the months immediately prior to the end of the compliance year. Second, 2007 was the last year of the self-contained first ETS trading period, with EUA prices close to zero, suggesting that a significant proportion of trading may have been driven by residual concerns at the end of the period. However, estimation results based on currently available data are available upon request.
} 


\section{Results and Discussion}

\subsection{Inter-Firm Purchases}

We first consider the demand side of the inter-company trade in EUAs (Table 5). The first stage of our estimation reveals that several company characteristics significantly predict participation in inter-company EUA trading on the buyer side. Company size is positively and significantly related with the probability to engage in EUA purchases. Our estimates for the full samples indicate that a one percent increase in turnover leads to a $4.5 \%$ and $3.3 \%$ increase in the probability to participate, respectively, when considering the full samples for each cross section. This finding corresponds to results from the empirical literature on international trade, which finds that larger firms are more likely to engage in trade. The log of the total value of a firm's EUA allocation available for trade ${ }^{20}$ is also found to increase the participation probability in both years, with a one-percent increase leading to a $4.2 \%$ and $4.3 \%$ increase in the participation probability, respectively. Thus, for the full sample the size of the effect of a firm-specific characteristic is on par with an EUETS-specific variable in its impact on the likelihood to participate in trading. Furthermore, we find a positive but insignificant effect of the relative value of the EUA allocation to the firm, as measured by the value of the annual EUA allocation as a share of firm size, on participation. Ownership structure also has a significant impact on participation in 2005, while being insignificant in 2006, at least for the full sample. We find that majority government-owned firms were $15 \%$ more likely to purchase EUAs externally in 2005. The firm's sector also has a significant impact on participation in both years. Having its main activity in the industrial sector rather in combustion reduces the participation probability by $17.6 \%$ and $15.9 \%$, respectively. ${ }^{21}$ However, this effect is much diminished when excluding the active firms from the sample. ${ }^{22}$ Thus, we find evidence of a more active allowance management in the combustion sector relative to the industrial sector. Other important firm characteristics, such as firm profitability and productivity are not found

\footnotetext{
${ }^{20}$ This variable measures the actual stock of EUAs transferred into the firms' accounts by the national registries during a particular compliance year, which is why the full sample is smaller for the 2005 compliance year, as some firms did not receive their allocation before the start of the 2006 compliance year.

${ }^{21}$ We performed additional regressions separately considering the samples of firms from the combustion and industrial sectors as a robustness test. The main results are broadly similar in terms of coefficient size and significance and are available upon request.

${ }^{22}$ The estimations involving the less-active samples are conducted based on a lower share of observations exhibiting a dummy indicating participation in the first stage, and thus a smaller number of non-zero observations in the second stage. Given the high share of non-participation in the less-active samples, the results should be treated with the appropriate caution. However, we feel reassured by the broad consistency of the coefficient estimates in terms of signs and significance across samples.
} 
to have a significant impact on participation. These results are in contrast to findings in the general trade literature. Finally, we find strong evidence that firms which were long on EUAs were significantly less likely to engage in inter-firm EUA purchases, across all samples and in both 2005 and 2006.

Table 5: Determinants of Inter-Firm EUA Purchases

\begin{tabular}{|c|c|c|c|c|}
\hline & \multicolumn{2}{|c|}{2005} & \multicolumn{2}{|c|}{2006} \\
\hline & Full Sample & Less Active & Full Sample & Less Active \\
\hline & & $\ln$ (Value of In & m Purchases) & \\
\hline \multirow[t]{2}{*}{$\ln$ (Value of EUA Stock) } & $0.830^{* * *}$ & $0.609^{* * *}$ & $0.749^{* * *}$ & $0.708^{* * *}$ \\
\hline & $(0.000)$ & $(0.000)$ & $(0.000)$ & $(0.000)$ \\
\hline \multirow[t]{2}{*}{ EUA Position: Long } & $-3.100^{* * *}$ & -2.376 & -1.243 & -1.905 \\
\hline & $(0.000)$ & $(0.169)$ & $(0.133)$ & $(0.482)$ \\
\hline \multirow[t]{2}{*}{$\ln$ (Turnover/Total Assets) } & 0.042 & 0.248 & 0.033 & 0.121 \\
\hline & $(0.910)$ & $(0.564)$ & $(0.846)$ & $(0.693)$ \\
\hline \multirow[t]{2}{*}{ Return on Assets } & 0.042 & 0.045 & 0.023 & 0.038 \\
\hline & $(0.196)$ & $(0.323)$ & $(0.237)$ & $(0.152)$ \\
\hline \multirow[t]{2}{*}{ Government-Owned } & 0.490 & 0.682 & 0.290 & 0.169 \\
\hline & $(0.420)$ & $(0.308)$ & $(0.440)$ & $(0.788)$ \\
\hline \multirow[t]{2}{*}{ Family-Owned } & $-3.845^{* *}$ & $-1.500^{* *}$ & 0.212 & 0.032 \\
\hline & $(0.020)$ & $(0.046)$ & $(0.659)$ & $(0.949)$ \\
\hline \multirow[t]{2}{*}{ Industry } & -0.364 & -0.680 & -0.472 & -0.264 \\
\hline & $(0.637)$ & $(0.477)$ & $(0.284)$ & $(0.570)$ \\
\hline \multirow[t]{2}{*}{ Inverse Mills Ratio } & 0.915 & 0.687 & -0.492 & 0.610 \\
\hline & $(0.395)$ & $(0.648)$ & $(0.676)$ & $(0.742)$ \\
\hline \multirow[t]{3}{*}{ Constant } & -0.087 & 2.931 & 1.603 & 1.255 \\
\hline & $(0.976)$ & $(0.223)$ & $(0.397)$ & $(0.283)$ \\
\hline & \multicolumn{4}{|c|}{ Participation: Inter-Firm Purchases } \\
\hline \multirow[t]{2}{*}{ Value of EUA Stock/Turnover } & 0.034 & 0.020 & 0.110 & 0.115 \\
\hline & $(0.677)$ & $(0.753)$ & $(0.514)$ & $(0.413)$ \\
\hline \multirow[t]{2}{*}{$\ln$ (Turnover) } & $0.045^{* * *}$ & $0.015^{*}$ & $0.033^{* * *}$ & 0.012 \\
\hline & $(0.000)$ & $(0.090)$ & $(0.003)$ & $(0.219)$ \\
\hline \multirow[t]{2}{*}{$\ln$ (Value of EUA Stock) } & $0.042^{* * *}$ & -0.001 & $0.043^{* * *}$ & -0.010 \\
\hline & $(0.000)$ & $(0.891)$ & $(0.000)$ & $(0.262)$ \\
\hline \multirow[t]{2}{*}{ EUA Position: Long } & $-0.323^{* * *}$ & $-0.286^{* * *}$ & $-0.454^{* * *}$ & $-0.513^{* * *}$ \\
\hline & $(0.000)$ & $(0.000)$ & $(0.000)$ & $(0.000)$ \\
\hline \multirow[t]{2}{*}{ ln(Turnover/Total Assets) } & -0.018 & -0.003 & 0.045 & 0.041 \\
\hline & $(0.602)$ & $(0.859)$ & $(0.209)$ & $(0.129)$ \\
\hline \multirow[t]{2}{*}{ Return on Assets } & 0.002 & 0.001 & -0.003 & -0.001 \\
\hline & $(0.569)$ & $(0.612)$ & $(0.376)$ & $(0.737)$ \\
\hline \multirow[t]{2}{*}{ Government-Owned } & $0.150^{* *}$ & 0.031 & -0.037 & -0.048 \\
\hline & $(0.014)$ & $(0.452)$ & $(0.508)$ & $(0.249)$ \\
\hline \multirow[t]{2}{*}{ Family-Owned } & -0.100 & -0.016 & -0.084 & 0.023 \\
\hline & $(0.162)$ & $(0.709)$ & $(0.255)$ & $(0.699)$ \\
\hline \multirow[t]{2}{*}{ Industry } & $-0.176^{* * *}$ & $-0.069^{* *}$ & $-0.159^{* * *}$ & $-0.069^{*}$ \\
\hline & $(0.000)$ & $(0.027)$ & $(0.001)$ & $(0.085)$ \\
\hline Observations & 608 & 503 & 666 & 510 \\
\hline Censored Observations & 445 & 445 & 406 & 406 \\
\hline Wald Chi2 & 59.90 & 51.07 & 201.47 & 164.68 \\
\hline Wald Chi2 p-value & 0.000 & 0.000 & 0.000 & 0.000 \\
\hline
\end{tabular}

Quantitatively the result is also very significant. Long firms were $32.3 \%$ less likely to participate in EUA purchases for the full 2005 sample, while this probability falls to $28.6 \%$ for the less-active sample. This effect strengthens in 2006, with the probability of non-participation increasing well above $40 \%$ in both samples. Thus, while market-specific 
factors such as the available stock of EUAs and the relative compliance position of the firm significantly predict the probability to engage in carbon permit trading, a number of company-specific characteristics are also significant, indicating that in the EU ETS both sets of determinants come together in influencing the firms' decision whether to trade.

We next turn to the relationship between the participation and amount equations. Our estimate of the inverse Mills ratio is insignificant in all cases for the 2005 and 2006 cross sections. Therefore, we find no evidence of a selection bias, suggesting that the decisions whether to engage in inter-firm EUA purchasing at all and how much to purchase were not significantly related. This finding is in contrast to the results in the general trade literature, suggesting that self-selection does not appear to be of the same importance as in the case of regular traded goods.

Considering the amount decision, we find that a larger initial EUA allocation leads to larger purchases in both years, suggesting that an increase in the value of the EUA stock by $1 \%$ increases purchases by between $0.6 \%$ and $0.83 \%$, depending on year and sample. We also find a significnat effect of ownership structure in the 2005 samples, with family-owned companies acquiring significantly fewer EUAs. Finally, we find that firms that were long on EUAs ex post bought significantly fewer EUAs in the 2005 full sample, ceteris paribus. However, this effect is neither significant in the less-active 2005 sample nor in either 2006 sample. Thus, the amount decision appears to be dominated by the market-specific factor allocation size.

\subsection{Inter-Firm Sales}

We next consider the supply side of the EU ETS (Table 6). Analogously to our results on the demand side, we find that neither firm productivity nor profitability significantly predict participation in the EUA trade. We find that the value of the EUA stock available for trading positively and significantly predicts the likelihood of engaging in the sale of EUAs both in 2005 and 2006. Coefficient estimates are larger than on the demand side, with a one percent increase in the value of a firm's initial EUA stock increasing its probability to participate in selling EUAs by around $10 \%$ in the full samples. The value of the EUA stock relative to the value of the firm is again mostly insignificant, as is firm size. The result on turnover is in contrast to our finding that firm size significantly predicts participation on the demand side of the EU ETS. Ex ante, we would expect transaction cost considerations to play a similar role on both sides of the EUA trade, meaning that 
larger firms should to be more likely to participate in the EUA trade. Therefore, this finding constitutes a puzzle. The results regarding the ownership and industry dummies are similar to our findings on the demand side regarding sign and significance for the 2005 cross section, while the absolute values of the coefficient estimates are generally larger. In particular, the industry dummy is still negative and highly significant in both years and for both samples, with the coefficient estimate suggesting a decrease in the participation probability by up to $23.6 \%$ if the firm's main activity lay outside the combustion category.

Table 6: Determinants of Inter-Firm EUA Sales

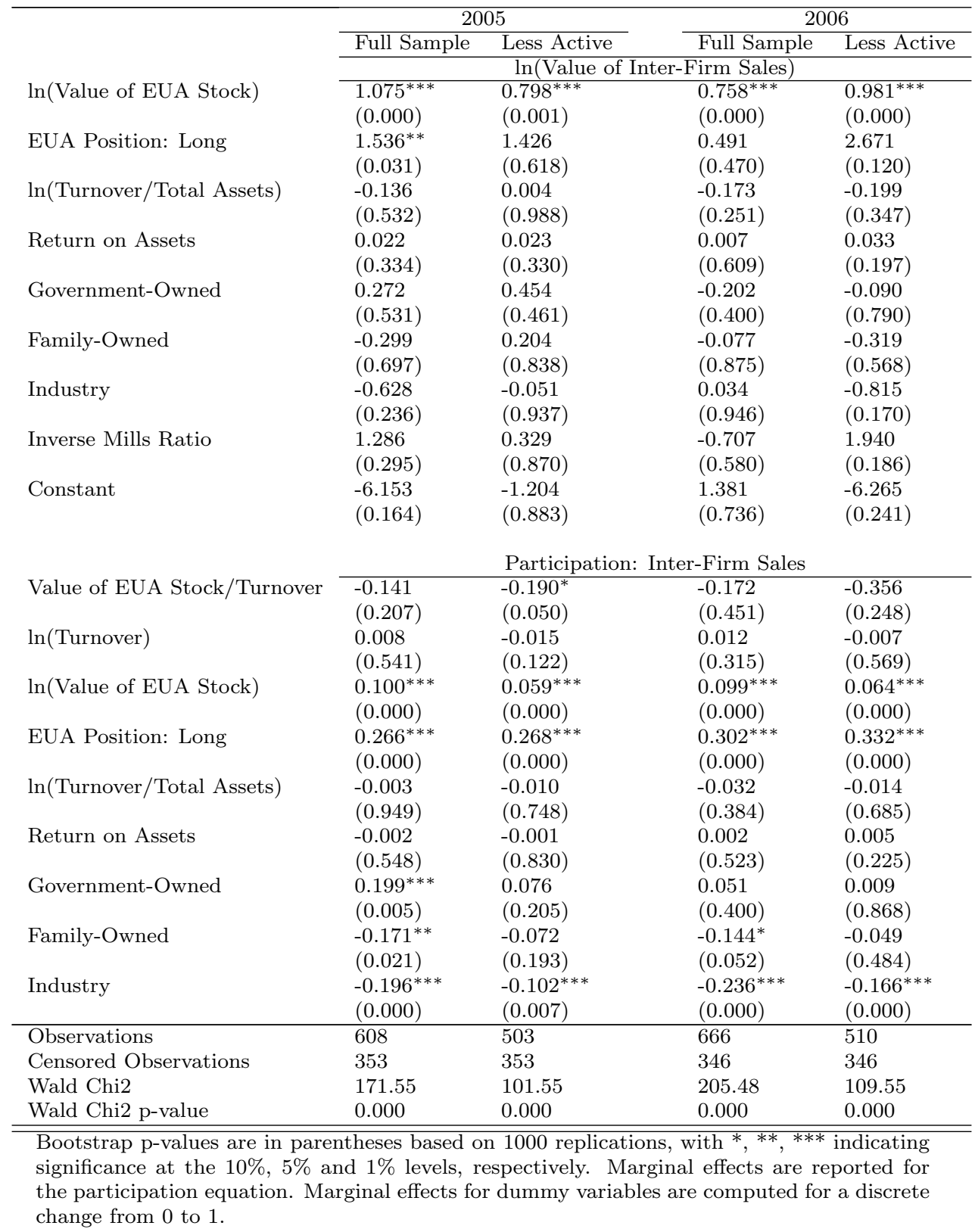

Furthermore, again we find a strongly significant effect on participation for firms that 
were long on allowances. Being long on allowances increased the probability to sell EUAs by some $26-33 \%$, in both years and both samples. Thus, it appears that the participation decision on the supply side was also driven by a combination of firm-specific and marketspecific factors during the first EU ETS compliance year, again partially analogous to findings from the wider trade literature. However, in the second year market-specific concerns appear to have dominated, apart from the distinction in trading probability between the combustion and industry sectors.

Our results on the inverse Mills ratio suggest that there is no significant selection bias on the supply side of the EU ETS, supporting our finding for the demand side in this respect. Again, this is in contrast to the results in the wider trade literature.

We then consider the amount decision on the supply side. As in the case of purchases, we find that a larger EUA allocation is positively and significantly related to the amount sold for both years and all samples, while the coefficient estimates are somewhat larger than their equivalents on the demand side. Analogously to the demand side we only find weak evidence of the firms' relative compliance position on the amount sold externally.

\subsection{Intra-Firm Transfers}

Finally, we estimate the determinants of intra-company transfers of EUAs, i.e. one installation of a company receiving EUAs from another installation within the same company (Table 7). While this part of the analysis does not belong to our main focus, we consider the drivers of firms' decisions to optimize their permit portfolio internally and compare it to our results on the inter-firm trade. ${ }^{23}$ For the analysis in this section we exclude companies consisting of only one installation, as they cannot conduct intra-firm trade with EUAs by definition, leading to smaller samples in this section. The determinants of the participation decision are similar to those of the participation decision in inter-company purchases in terms of the sign and significance of the value of the firm's EUA stock, as well as of the ownership and industry dummies for the 2005 cross section. In contrast to the inter-firm regressions the EUA-stock-to-turnover ratio enters with a negative sign, although it is only significant in the 2006 samples. ${ }^{24}$ Productivity and profitability also do not significantly predict participation in intra-firm EUA transfers. The key difference

\footnotetext{
${ }^{23}$ The results in this section are identical no matter whether we consider intra-firm "sales" or "purchases", as they exactly mirror each other.

${ }^{24}$ Note that we have rescaled this variable by a factor of 1,000 to avoid having to present the otherwise very small coefficients.
} 
compared to inter-firm EUA purchases is the role of firm size, which is not found to significantly enter the participation decision. Also, in contrast to its role in inter-firm purchases of EUAs, the effect of the relative EUA position is found to be weaker, both statistically and quantitatively.

Table 7: Determinants of Intra-Firm EUA Transfers

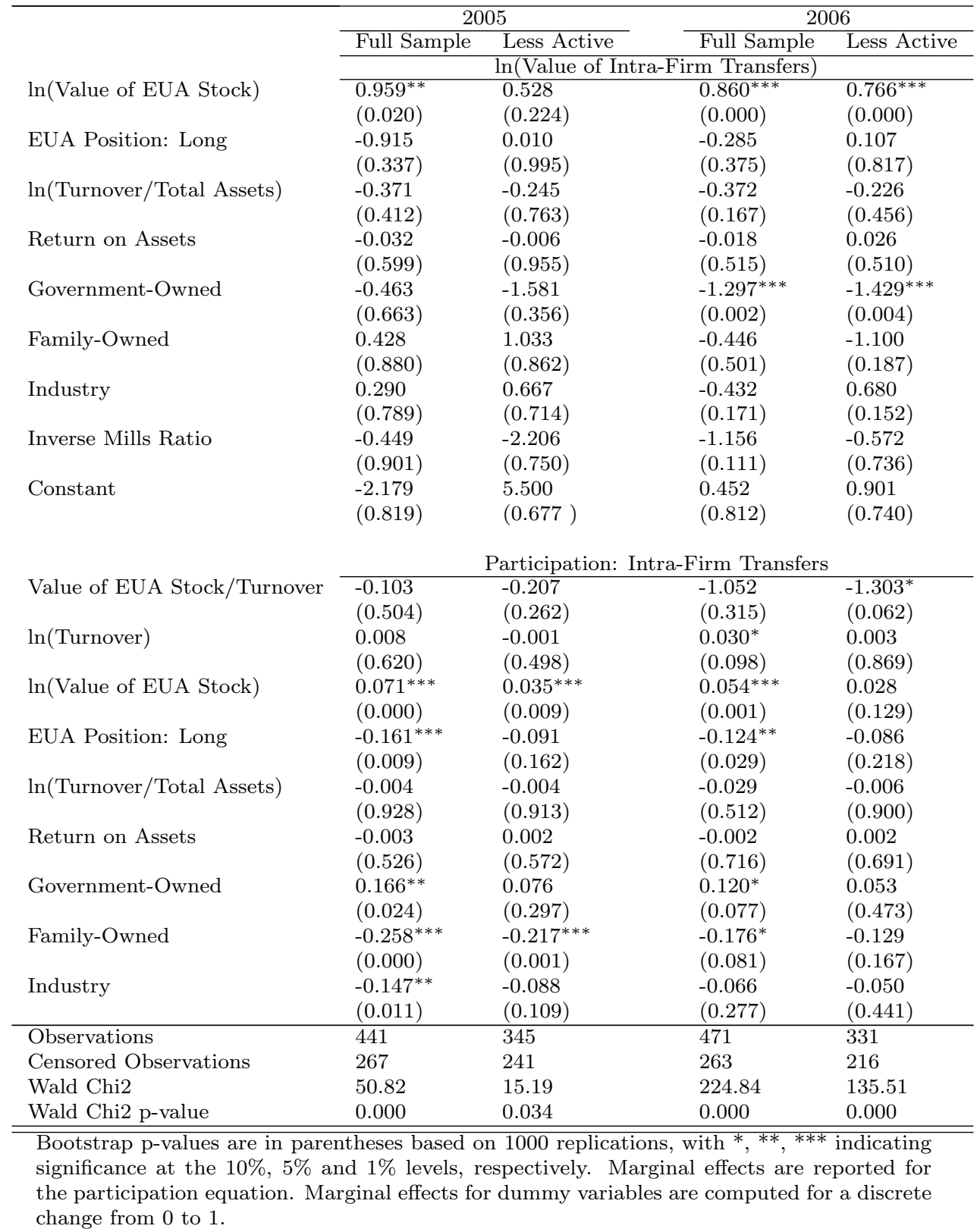

Thus, the firms' EUA position appeared to have a weaker impact on internal than on external permit portfolio optimization. This result is not unexpected, as the dummy indicating the relative EUA position contains information on the position of the firm as a whole. We expect that the extent of internal EUA trading should also be driven by 
the distribution of long and short positions among a firm's installations. Therefore, the variable measuring the firm's overall position would be expected to be less influential in the case of intra-firm trading. ${ }^{25}$ As in the case of inter-firm trade both on the supply and demand sides, the intra-firm EUA trade also does not exhibit a significant selection bias.

In line with our results on the inter-firm trade, we find that the amount of EUAs transferred internally significantly increases with the value of the EUA stock available to the firm in the respective compliance year. A one-percent-increase in the EUA stock approximately resulted in increases in the intra-firm EUA trade by between $0.76 \%$ and $0.96 \%$. The government dummy is negative and strongly significant in the 2006 samples, while being insignificant in 2005 .

Hence, our results suggest that both the intra-firm and inter-firm EUA trade share a subset of determinants, with firm-specific factors mostly affecting the participation decision in both cases.

\section{Conclusion}

The establishment of the EU ETS has turned the right to emit $\mathrm{CO}_{2}$ into an intermediate good for the firms required to comply with EU ETS regulations, leading to a decision whether to source compliance within the firm's boundaries or to trade for it through the EU ETS. However, free allocation, abatement and intertemporal flexibility have created the potential for non-trading on the firm level in any given period, leading to possible self-selection into trading. This paper seeks to understand the drivers of firms' decisions to engage in trading carbon emission permits during any particular year, as well as the intensity of their trading activity. We consider these questions based on a newly constructed dataset mapping account-based transactions data on the first two compliance years of the European Emission Trading Scheme to the level of firms. While focusing on the behavior of $\mathrm{CO}_{2}$ emitters required to participate in the EU ETS by law, our mapping contains information from both operator and person holding accounts held by emitting firms. We combine the data on permit holdings and trading with firm-level balance sheet information capturing key characteristics of the firms involved.

A thorough descriptive analysis of the microstructure of the EU ETS sets the stage for our further quantitative analysis. We estimate a corner solution model for the supply

\footnotetext{
${ }^{25}$ However, for the purpose camparability we choose to keep our set of explanatory variables consistent across all regressions.
} 
and demand sides of both the inter-firm and intra-firm permit trade, while allowing for self-selection into trading. We find that firm-specific characteristics existing independently of the EU ETS such as size, sector, and ownership structure play a significant role in the firms' decision whether to participate in the permit trade at all. Notably, the role of firm size differs on the demand and supply sides of the inter-firm trade. In contrast to the general literature on the firm-level determinants of the trade in goods we do not find that productivity significantly predicts either participation in the permit trade or the amounts traded. Furthermore, market-specific factors, i.e. characteristics that firms only exhibit in relation to the EU ETS, such as the value of the firms' free permit allocation and its relative compliance position, also significantly predict participation in the permit trade. However, the amounts traded are found to be mostly determined by these market-specific factors.

Our results suggest that the set-up of the EU ETS with free allocation and intertemporal flexibility afforded firms some leeway to exhibit behavior similar to the patterns revealed by the existing literature on firm-level determinants of the trade in goods, particularly regarding participation in the permit trade. However, we also find that amounts of allowances traded are ultimately driven by features of firms directly related to their standing in the EU ETS.

\section{References}

[1] Abrell, J., Ndoye Faye, A., and Zachmann, G. 2011. Assessing the Impact of the EU ETS Using Firm Level Data. BRUEGEL Working Paper 2011/08.

[2] Antras, P., and Helpman, E. 2004. Global Sourcing. Journal of Political Economy 112(3), pp. 552-580.

[3] Baldwin, R., and Harrigan, J. 2011. Zeros, Quality, and Space: Trade Theory and Trade Evidence. American Economic Journal: Microeconomics 3, pp. 60-88.

[4] Benz, E., and S. Trück. 2009. Modeling the Price Dynamics of CO2 Emission Allowances. Energy Economics 31, pp. 4-15.

[5] Bernard, A. B., and Jensen, J. B. 1999. Exceptional Exporter Performance: Cause, Effect, or Both? Journal of International Economics 47(1), pp. 1-25. 
[6] Bernard, A. B., Jensen, J. B., Redding, S. J., and Schott, P. K. 2009. The Margins of U. S. Trade. American Economic Review Papers and Proceedings 99(2), pp. 487-493.

[7] Bernard, A. B., Jensen, J. B., Redding, S. J., and Schott, P. K. 2010. Intra-Firm Trade and Product Contractibility. NBER Working Paper 15881.

[8] Bernard, A. B., Jensen, J. B., Redding, S. J., and Schott, P. K. 2011. The Empirics of Firm Heterogeneity and International Trade. LSE CEP Discussion Paper No. 1084.

[9] Bredin, D., and C. Muckley. 2011. An Emerging Equilibrium in the EU Emissions Trading Scheme. Energy Economics 33, pp. 353-362.

[10] Ellerman, A. D., Connery, F. J., and Perthuis, C. D. 2010. Pricing Carbon. Cambridge and New York: Cambridge University Press.

[11] Fell, H. 2010. EU-ETS and Nordic Electricity: A CVAR Analysis. The Energy Journal $31(2)$, pp. 1-25.

[12] Greenaway, D., and Kneller, R. 2007. Firm Heterogeneity, Exporting and Foreign Direct Investment. The Economic Journal 117, pp. 134-161.

[13] Heckman, J. 1979. Sample Selection Bias as a Specification Error. Econometrica 47, pp. 153-161.

[14] Hintermann, B. 2010. Allowance Price Drivers in the First Phase of the EU ETS. Journal of Environmental Economics and Management 59, pp. 43-56.

[15] Jaraite, J., Convery, F., and Di Maria, C. 2010. Transaction Costs for Firms in the EU ETS: Lessons from Ireland. Climate Policy 10, pp. 190-215.

[16] Jaraite, J., and Kazukauskas, A. 2012. Firm Trading Behaviour and Transaction Costs in the European Union's Emission Trading System: An Empirical Assessment. CERE Working Paper 2012:9.

[17] Melitz, M. J. 2003. The Impact of Trade on Intra-Industry Reallocations and Aggregate Industry Productivity. Econometrica 71, pp. 1695-725.

[18] Montgomery, W. D. 1972. Markets in Licenses and Efficient Pollution Control Programs. Journal of Economic Theory 5, pp. 395-418. 
[19] Radner, R. 1996. Bounded Rationality, Indeterminacy, and the Theory of the Firm. The Economic Journal 106, pp. 1360-1373.

[20] Roberts, M. J., and Tybout, J. 1997. The Decision to Export in Colombia: An Empirical Model of Entry with Sunk Costs. American Economic Review 87(4), pp. $545-564$.

[21] Simon, H. A. 1979. Rational Decision Making in Business Organizations. American Economic Review 69(4), pp. 493-513.

[22] Stavins, R. N. 1995. Transaction Costs and Tradeable Permits. Journal of Environmental Economics and Management 29, pp. 133-148.

[23] Trotignon, R., and Delbosc, A. 2008. Allowance Trading Patterns during the EU ETS Trial Period: What Does the CITL Reveal? Caisse des Depots Climate Report $13 / 2008$.

[24] Trotignon, R., and Ellerman, A. D. 2008. Compliance Behavior in the EU ETS: Cross Border Trading, Banking and Borrowing. MIT CEEPR Working Paper 08-012.

[25] Wooldridge, J. M. 2010. Econometric Analysis of Cross Section and Panel Data. Cambridge and London: The MIT Press. 


\section{Appendix: List of Variables}

\section{Dependent Variables}

\section{Quantitative Variables}

- $\ln$ (Value of inter-firm sales): Natural logarithm of the value of EUA flows that leave the firm, drawn from CITL transactions data. We use the average EUA spot price in Euro for each compliance year to compute the value of this and the other value variables.

- $\ln$ (Value of inter-firm purchases): Natural logarithm of the value of EUA flows that enter the firm, drawn from CITL transactions data.

- $\ln$ (Value of intra-firm transfers): Natural logarithm of the value of EUA flows that leave one installation and enter another installation of the same firm in the same year, drawn from CITL transactions data, computed for firms consisting of more than one installation.

\section{Categorical Variables}

- Participation: Inter-firm sales: $=1$ if the firm's value of inter-firm sales $>0$ in a particular compliance year; and $=0$ otherwise.

- Participation: Inter-firm purchases: $=1$ if the firm's value of inter-firm purchases $>0$ in a particular compliance year; and $=0$ otherwise.

- Participation: Intra-firm transfers: $=1$ if the firm's value of intra-firm transfers $>0$ in a particular compliance year; and $=0$ otherwise.

\section{Independent Variables}

\section{Quantitative Variables}

- $\ln$ (Value of EUA stock): Natural logarithm of the value of each firm's EUA stock in Euro, as available for trading in each compliance year. This variable is based on CITL transactions data, and thus may differ from the firm's NAP allocation, e.g. due to delays in some national registries becoming operational (Poland and Italy are cases in point). 
- $\ln$ (Turnover): Natural logarithm of the firm's annual turnover as reported in AMADEUS, in Euro.

- Value of EUA stock / turnover: Ratio of the value of the firm's EUA stock to its turnover. This variable has been rescaled to avoid very small coefficients.

- $\ln$ (Turnover/total assets): Natural logarithm of the ratio of the firm's annual turnover to the value of its total assests as reported in AMADEUS, in Euro.

- Return on assets: Return on assets as reported in AMADEUS, in percent.

\section{Categorical Variables}

- Government-owned: $=1$ if the government owns more than $50 \%$ of the firm; and $=$ 0 otherwise. Based on AMADEUS data.

- Family-owned: $=1$ if a single person or a family owns more than $50 \%$ of the firm; and $=0$ otherwise. Based on AMADEUS data.

- EUA position: long: = 1 if the firm's allocation is larger than its verified emissions in that compliance year, based on CITL compliance data; and $=0$ otherwise.

- Industry: = 1 if the majority of the firm's emissions were generated in installations classified outside of the combustion category based on the main activity codes from the CITL compliance data; and $=0$ otherwise. 